\title{
Improve the Anaerobic Biodegradability by Copretreatment of Thermal Alkali and Steam Explosion of Lignocellulosic Waste
}

\author{
Muhammad Abdul Hanan Siddhu, ${ }^{1}$ Jianghao Li, ${ }^{1}$ Jiafu Zhang, ${ }^{1}$ Yan Huang, \\ Wen Wang, ${ }^{1}$ Chang Chen, ${ }^{1,2}$ and Guangqing Liu ${ }^{1}$ \\ ${ }^{1}$ Biomass Energy and Environmental Engineering Research Center, College of Chemical Engineering, \\ Beijing University of Chemical Technology, Beijing 100029, China \\ ${ }^{2}$ College of Life Science and Technology, Beijing University of Chemical Technology, Beijing 100029, China
}

Correspondence should be addressed to Chang Chen; chenchang@mail.buct.edu.cn and Guangqing Liu; gqliu@mail.buct.edu.cn

Received 6 December 2015; Revised 28 February 2016; Accepted 13 March 2016

Academic Editor: José L. Campos

Copyright (C) 2016 Muhammad Abdul Hanan Siddhu et al. This is an open access article distributed under the Creative Commons Attribution License, which permits unrestricted use, distribution, and reproduction in any medium, provided the original work is properly cited.

\begin{abstract}
Effective alteration of the recalcitrance properties like crystallization of cellulose, lignin shield, and interlinking of lignocellulosic biomass is an ideal way to utilize the full-scale potential for biofuel production. This study exhibited three different pretreatment effects to enhance the digestibility of corn stover (CS) for methane production. In this context, steam explosion (SE) and thermal potassium hydroxide $\left(\mathrm{KOH}-60^{\circ} \mathrm{C}\right)$ treated CS produced the maximal methane yield of 217.5 and $243.1 \mathrm{~mL} / \mathrm{g}_{\mathrm{vs}}$, which were $40.0 \%$ and $56.4 \%$ more than untreated CS $\left(155.4 \mathrm{~mL} / \mathrm{g}_{\mathrm{vs}}\right)$, respectively. Copretreatment of thermal potassium hydroxide and steam explosion (CPTPS) treated CS was highly significant among all treatments and improved $88.46 \%\left(292.9 \mathrm{~mL} / \mathrm{g}_{\mathrm{vs}}\right)$ methane yield compared with untreated CS. Besides, CPTPS also achieved the highest biodegradability up to $68.90 \%$. Three kinetic models very well simulated dynamics of methane production yield. Moreover, scanning electron microscopy (SEM), Fourier transform infrared (FTIR), and X-ray diffraction (XRD) analyses declared the most effective changes in physicochemical properties after CPTPS pretreatment. Thus, CPTPS might be a promising approach to deconstructing the recalcitrance of lignocellulosic structure to improve the biodegradability for AD.
\end{abstract}

\section{Introduction}

China is the second largest maize producer worldwide. Mostly, maize is cultivated in the central and north part of China. According to crop ratio index and China statistic year book, around 400 MTs of corn stover (CS) were generated in 2012 [1]. But approximately, two-thirds of produced CS was not utilized. Farmers burnt or threw away this portion of CS, because of quick preparation of land for next crop cultivation, high input cost for collection, and cheap market prices. This practice not only caused the natural resource depletion but also stimulated many serious environmental issues on local and regional scale, for example, air pollution, global warming, climate change, and so forth [2]. Hence, it is a great responsibility standing on researcher's shoulder to develop solution for effective utilization of CS by conserving environment as well as the natural resource.

Anaerobic digestion (AD) is a complicated biological process for treatment of various types of organic wastes (municipal waste, agricultural waste, industrial waste, etc.) for generation of biogas as well as protecting our environment [3]. However, biodegradability and AD performance of organic waste depend on its characteristics. Agricultural sector is key contributor for generation of lignocellulosic waste, and the main components of this waste are cellulose, hemicellulose, and lignin. Physicochemical quantitative and qualitative properties of lignocellulosic biomass such as accessible surface area, crystallization nature, lignin polymerization, and cross linkages of cell wall should be deconstructed for improving the anaerobic digestibility. Thus, 
effective and moderate conditions of different pretreatment methods can be used to overcome recalcitrance nature of biomass in order to achieve effective utilization and increase the anaerobic digestibility [4].

Steam explosion (SE) is an environmental friendly method for the pretreatment of lignocellulosic biomass [5]. In SE pretreatment, lignocellulosic biomass undergoes saturated steam at high pressure for short time, and then the pressure is released suddenly. This process causes the physical disruption of lignocellulosic biomass such as rupturing the cross linkages of cell walls and transmutation of hemicellulose [6]. Thus, more efforts should be addressed to use the SE pretreatment for lignocellulosic biomass to improve the hydrolysis and anaerobic digestibility [7-9].

In the past years, alkali pretreatment has also been extensively studied to enhance the hydrolysis of lignocellulosic biomass. Overall alkali pretreatment performance is to swell and solubilize lignocelluloses with an outcome of enhancing the biodegradability. Besides, thermal alkali pretreatment of lignocellulosic biomass can effectively destroy the recalcitrance properties, while some inhibitory substances start to produce during the treatment at high temperature $\left(>100^{\circ} \mathrm{C}\right)$ with $\mathrm{NaOH}$. Some studies reported that treatment of biomass with mild thermal $\mathrm{NaOH}$ (lower than $100^{\circ} \mathrm{C}$ ) was more effective way to remove lignin, enhance hydrolysis, and improve the biodegradability for $\mathrm{AD}$ as compared to room temperature [10-12]. However, some studies reported the issues related to high loading of $\mathrm{NaOH}$ like toxic to microorganisms, soil salinity, and difficulty of recycling [13]. So considering these issues, potassium hydroxide $(\mathrm{KOH})$ might be preferred over $\mathrm{NaOH}$, because $\mathrm{KOH}$ black liquor can be used as soil reclamation and as fertilizer in agriculture sector. Thus, $\mathrm{KOH}$ pretreatment at mild thermal might be more suitable and effective condition to enhance the hydrolysis of lignocellulosic biomass for AD.

Copretreatment of thermal $\mathrm{KOH}$ and SE might have more synergistic effect to overcome the recalcitrance nature of lignocellulosic biomass and improve digestibility for AD.

The goals of this work were to (1) measure the methane production potential and digestion performance of untreated, thermal $\mathrm{KOH}$ treated, and CPTPS treated CS; (2) determine the most effective pretreatment method to improve the CS digestibility; and (3) compare the physicochemical structure changes of CS after different pretreatments by scanning electron microscopy (SEM), Fourier transform infrared (FTIR), and X-ray diffraction (XRD) analyses.

\section{Materials and Methods}

2.1. Substrate and Inoculum. CS was obtained from Deqingyuan Company's farm, Beijing, China. CS was chopped by a 9SC-360 kneading machine (Shuncheng, China). Then CS was air-dried and bigger particle size was manually cut down by scissors in the length range of $1.5-2 \mathrm{~cm}$. The dried samples of CS were kept in airtight plastic bags and stored at $4^{\circ} \mathrm{C}$ for later use. The inoculum for this study was the effluent of Nanwu Biogas Plant operated in Beijing, China.
2.2. Thermal Potassium Hydroxide Pretreatment. Four different concentrations $(0.5 \%, 1.0 \%, 1.5 \%$, and $2.0 \%, \mathrm{~W} / \mathrm{V})$ of $\mathrm{KOH}$ were added to $1.5 \mathrm{~L}$ plastic boxes. After this, CS was soaked into aqueous $\mathrm{KOH}$ solutions to increase moisture content up to $90 \%$ by using (1) [14]. Then the alkaline pretreatment was carried out at $60^{\circ} \mathrm{C}$ for $12 \mathrm{~h}$, because low temperature (below $80^{\circ} \mathrm{C}$ ) should be more preferable since production of inhibitory substances may occur during long period of thermal pretreatment at high temperature [10]. Stirring of each box was carried out every $4 \mathrm{~h}$ for $1 \mathrm{~min}$ during the thermal $\mathrm{KOH}$ pretreatment. After completion of the thermal pretreatment, CS was squeezed and put into airtight bags and stored at $4^{\circ} \mathrm{C}$ for next study:

$$
\operatorname{MC}(\%)=\left(1-\frac{\text { dry weight of CS }}{\text { weight of CS }+ \text { water added }}\right) \times 100 \text {. }
$$

\subsection{Copretreatment of Thermal Potassium Hydroxide and} Steam Explosion (CPTPS). CPTPS was two-step copretreatment of CS with thermal $\mathrm{KOH}$ and SE. In this process, CS was pretreated with $0.5 \%$ and $1.5 \% \mathrm{KOH}$ at $60^{\circ} \mathrm{C}$ for $12 \mathrm{~h}$ and then steam-exploded at $1.2 \mathrm{MPa}$ for $10 \mathrm{~min}$. After completing this pretreatment, CS was packed in two airtight bags and kept at $4^{\circ} \mathrm{C}$. One bag was used for anaerobic digestion, while sample of second bag was dried at $60^{\circ} \mathrm{C}$ for 3 days for physicochemical analysis.

2.4. Batch Anaerobic Digestion Tests. Anaerobic batch digestion tests of untreated and treated CS were conducted in $1-\mathrm{L}$ serum bottles. All the anaerobic digestion setup was triplicated [15]. All the digesters were fed 1:1 ratio of substrate to inoculum $(S / I)$ on the basis of VS [16]. Working volume of each digester was adjusted to $500 \mathrm{~mL}$ by addition of deionized water. Each digester headspace was flushed with $99.0 \%$ pure argon for $4 \mathrm{~min}$ to ascertain the anaerobic atmosphere. Then rubber stopper and screw cap were fixed to digesters for sustaining the anaerobic conditions, before being placed in an incubator for running $\mathrm{AD}$ at $37^{\circ} \mathrm{C}$ for 28 days. Two parallel blank digesters containing the same quantity of inoculum were run in order to correct the methane production. All digesters were shaken twice manually each day for $1 \mathrm{~min}$ during the digestion time.

2.5. Analytical Methods. APHA standard methods were used to determine the total solid (TS), volatile solid (VS), and fixed solid (FS), of CS and inoculum [17]. Total ammonia nitrogen (TAN) and total alkalinity (TA) in the effluent were measured according to $\mathrm{Li}$ et al.s reported methods [18]. Elemental compositions ( $\mathrm{C}, \mathrm{H}, \mathrm{N}$, and $\mathrm{S}$ ) of $\mathrm{CS}$ and inoculum were measured by elemental analyzer (Vario Elcube, Germany). The oxygen content of CS on VS basis was estimated by assumption of $\mathrm{C}+\mathrm{H}+\mathrm{O}+\mathrm{N}=99.5 \%$ [19]. The $\mathrm{pH}$ of each digester was measured by a le $438 \mathrm{pH}$ electrode (Mettler Toledo, USA) [20]. Van Soest et al's reported method for measuring lignocellulosic content (cellulose, hemicellulose, and lignin) of CS was used [21].

Daily biogas production was measured by testing the pressure in the headspace of each digester. Pressure in the 
headspace was determined by a 3151 WAL-BMP-Test system pressure gauge with the precision of $0.1 \%$ (based on the gauge range) manufactured by WAL Mess- und Regelsysteme $\mathrm{GmbH}$, Germany [22]. After this, daily biogas production was calculated by using the following equation [23]:

$$
V_{\text {biogas }}=\Delta P \times V_{\text {head }} \times \frac{C}{(R \times T)},
$$

where $V_{\text {biogas }}$ stands for daily biogas volume (L), $\Delta P$ represents absolute pressure difference $(\mathrm{MPa}), V_{\text {head }}$ is volume of the headspace (L), $C$ expresses gas molar volume under standard condition $(22.4 \mathrm{~L} / \mathrm{mol}), T$ stands for absolute temperature $(\mathrm{K})$, and $R$ is universal gas constant $(8.314 \mathrm{~J} / \mathrm{K} / \mathrm{mol})$.

Biogas composition $\left(\mathrm{CH}_{4}, \mathrm{H}_{2}\right.$, and $\left.\mathrm{CO}_{2}\right)$ was measured by a 7890A gas chromatograph (Agilent, USA) equipped with a thermal conductivity detector. A Hitachi S-4700 (Japan) scanning electron microscopy (SEM) at a magnification of $500 \mathrm{x}$ was used to investigate the morphology of untreated and treated CS. Fourier transform infrared (FTIR) technique was applied to record the spectra of untreated and treated CS by using a Nicolet 6700 FTIR spectrophotometer (Thermo Fisher Scientific, Waltham, MA) equipped with a DLaTGS detector in the range of $4000-400 \mathrm{~cm}^{-1}$. Fine power of $2 \mathrm{mg}$ of untreated and treated CS was mixed with $100 \mathrm{mg}$ of $\mathrm{KBr}$ and compacted into pellets for examination. Change in crystallinity of CS before and after the pretreatment was compared by using X-ray diffraction (XRD) analysis. Germany Bruker D8-Advance with $\mathrm{Cu} \mathrm{K} \alpha$ radiation was used to analyze the crystallinity features of CS. Scans were obtained from $2 \theta$ of $5-60^{\circ}$ at a rate of $5^{\circ} / \mathrm{min}$ and the index (CrI) was calculated by following equation of Sun et al. [24]:

$$
\operatorname{CrI}(\%)=\left(\frac{I_{002}-I_{18^{\circ}}}{I_{002}}\right) \times 100,
$$

where CrI refers to crystallinity index (\%), $I_{002}$ expresses the maximal scattered intensity on the 002 lattice plane at main peak around $22^{\circ}$, and $I_{18^{\circ}}$ stands for amorphous zone scattered intensity at $2 \theta$ of $18^{\circ}$.

2.6. Theoretical Methane Yield (TMY). Theoretical methane yield (TMY) on the basis of different organic elements presented in the CS was calculated by Buswell formula as shown in (4) and (5) [25]. One has

$$
\begin{aligned}
\mathrm{C}_{n} \mathrm{H}_{a} \mathrm{O}_{b} \mathrm{~N}_{c}+\left(n-\frac{a}{4}-\frac{b}{2}+\frac{3 c}{4}\right) \mathrm{H}_{2} \mathrm{O} \\
\longrightarrow\left(\frac{n}{2}+\frac{a}{8}-\frac{b}{4}-\frac{3 c}{8}\right) \mathrm{CH}_{4} \\
\quad+\left(\frac{n}{2}-\frac{a}{8}+\frac{b}{4}+\frac{3 c}{8}\right) \mathrm{CO}_{2}+c \mathrm{NH}_{3} \\
\mathrm{TMY}\left(\frac{\mathrm{mL} \mathrm{CH}_{4}}{\mathrm{~g} \mathrm{VS}}\right) \\
=\frac{22.4 \times 1000 \times(n / 2+a / 8-b / 4-3 c / 8)}{12 n+a+16 b+14 c} .
\end{aligned}
$$

2.7. Biodegradability $\left(B_{d}\right)$. Anaerobic biodegradability $\left(B_{d}\right)$ of CS during the digestion was calculated on the basis of experimental methane yield (EMY) and theoretical methane yield (TMY), and the methodology was based on Elbeshbishy formula [26]:

$$
B_{d}(\%)=\frac{\mathrm{EMY}}{\mathrm{TMY}} \times 100
$$

2.8. Kinetics Analysis. Three different models (first-order, modified Gompertz, and Cone) were applied to simulate and understand the kinetics of cumulative methane yields [27].

Fist-order model is as follows:

$$
B=B_{0}[1-\exp (-k t)] \text {. }
$$

Modified Gompertz model is as follows:

$$
B=B_{0} \exp \left\{-\exp \left[\frac{\mu_{m} e}{B_{0}}(\lambda-t)+1\right]\right\} .
$$

Cone model is as follows:

$$
B=\frac{B_{0}}{\left[1+(k t)^{-n}\right]},
$$

where $B$ represents the cumulative methane yield $\left(\mathrm{mL} / \mathrm{g}_{\mathrm{vs}}\right)$; $B_{0}$ is the ultimate methane yield $\left(\mathrm{mL} / \mathrm{g}_{\mathrm{vs}}\right) ; k$ stands for the first-order rate constant $(1 / \mathrm{d}) ; k$ is the first-order rate constant; $\mu_{m}$ refers to the maximum methane production rate $\left(\mathrm{mL} / \mathrm{g}_{\mathrm{vs}} / \mathrm{d}\right) ; \lambda$ means the lag phase time $(\mathrm{d}) ; e$ is equal to $2.72 ; t$ represents the anaerobic digestion time (d); and $n$ is for shape factor (dimensionless).

\section{Results and Discussion}

3.1. Characteristics of CS and Inoculum. Characterization of the CS and inoculum has been illustrated in Table 1. CS was comprised of TS and VS content of $93.99 \%$ and $90.02 \%$, respectively, whereas VS to TS proportion was $95.77 \%$, which indicated high organic content in CS and high biogas production potential. Lignocellulosic constituent of CS was comprised of $44.32 \%$ of cellulose, $33.54 \%$ of hemicellulose, and $8.28 \%$ of lignin, while more than $75 \%$ of lignocellulosic content indicated a slow hydrolysis, long digestion time, and less volume of biogas yield achievable. On the elemental composition basis of CS, the organic content was formulated as $\mathrm{C}_{43.82} \mathrm{H}_{69.88} \mathrm{O}_{33.77} \mathrm{~N}$, and TMY of CS was calculated to be $425.1 \mathrm{~mL} \mathrm{CH}_{4} / \mathrm{g}_{\mathrm{vs}}$ by using (5).

\subsection{Anaerobic Digestion of Thermal Potassium Hydroxide} Treated Corn Stover. Thermal KOH treatment effects on daily and cumulative methane yields were presented in Figure 1. Highest peaks of daily methane yield of thermal $\mathrm{KOH}$ treated and untreated CS were appeared within the first five days of digestion, while maximum daily methane yield of thermally $60^{\circ} \mathrm{C}$ of $0.5 \%, 1.0 \%, 1.5 \%$, and $2.0 \% \mathrm{KOH}$ treated CS was $11.0 \pm 0.60,19.7 \pm 2.30,48.1 \pm 0.08$, and $45.4 \pm 2.80 \mathrm{~mL} / \mathrm{g}_{\mathrm{vs}}$, respectively. However, no significant improvement in daily maximum methane yield of thermally $60^{\circ} \mathrm{C}$ of $1.5 \%$ to $2.0 \%$ 


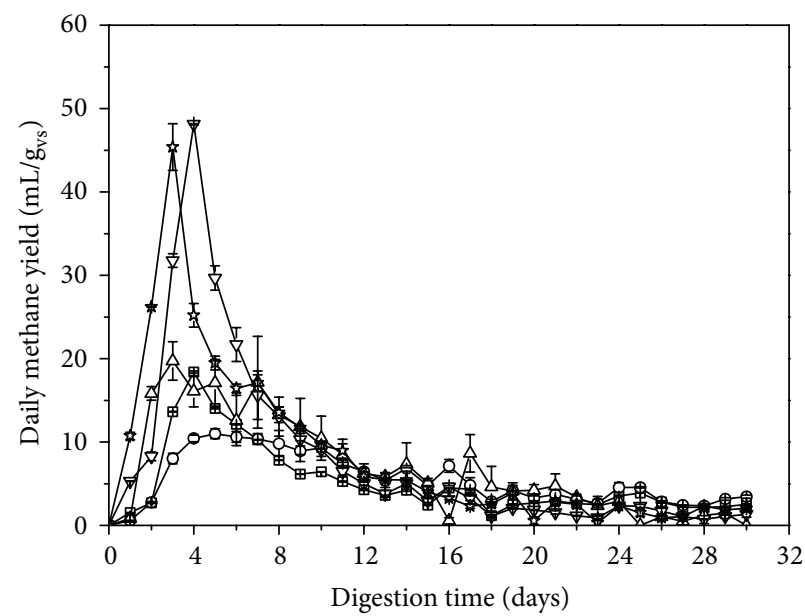

$\rightarrow-$ Untreated CS

-0- $0.5 \% \mathrm{KOH}-60^{\circ} \mathrm{C}$ treated CS

$\triangle-1.0 \% \mathrm{KOH}-60^{\circ} \mathrm{C}$ treated $\mathrm{CS}$

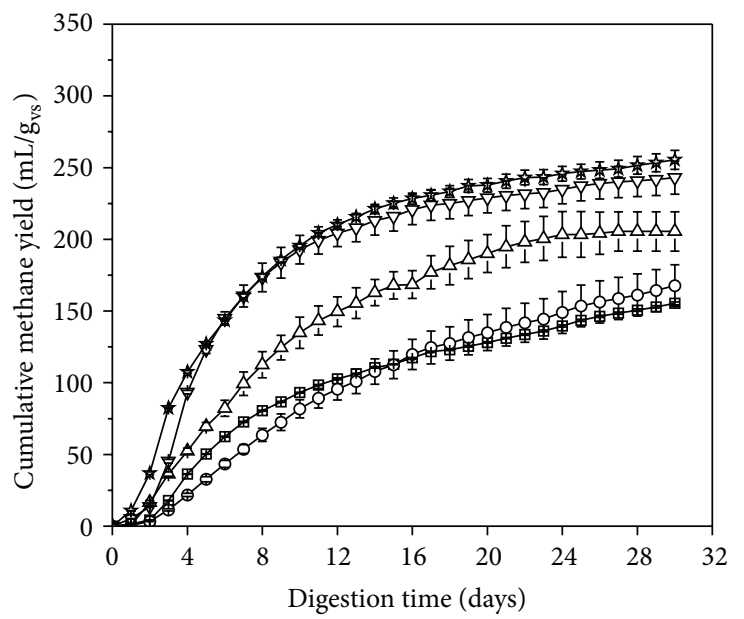

$\rightarrow-$ Untreated CS $\rightarrow-1.5 \% \mathrm{KOH}-60^{\circ} \mathrm{C}$ treated CS

$-0.5 \% \mathrm{KOH}-60^{\circ} \mathrm{C}$ treated CS $\longleftarrow 2.0 \% \mathrm{KOH}-60^{\circ} \mathrm{C}$ treated CS

$\triangle-1.0 \% \mathrm{KOH}-60^{\circ} \mathrm{C}$ treated $\mathrm{CS}$

Figure 1: Methane yields of untreated and $\mathrm{KOH}-60^{\circ} \mathrm{C}$ treated CS. Error bars were obtained based on $n=3$.

TABLE 1: Characteristics of CS and inoculum.

\begin{tabular}{lcc}
\hline Parameter & CS & Inoculum \\
\hline${\text { TS }(\%)^{\mathrm{a}}}^{\mathrm{a}}$ & 93.99 & 7.25 \\
VS (\%) & 90.02 & 3.52 \\
$\mathrm{FS}(\%)^{\mathrm{a}}$ & 3.98 & 3.73 \\
VS/TS (\%) & 95.77 & 48.58 \\
$\mathrm{pH}$ & $\mathrm{ND}$ & 7.95 \\
$\mathrm{C}(\%)^{\mathrm{b}}$ & 43.57 & 31.33 \\
$\mathrm{H}(\%)^{\mathrm{b}}$ & 5.79 & 4.23 \\
O $(\%)^{\mathrm{b}}$ & 44.77 & $\mathrm{ND}$ \\
$\mathrm{N}(\%)^{\mathrm{b}}$ & 1.16 & 2.85 \\
$\mathrm{C} / \mathrm{N}(\%)$ & 37.56 & 10.99 \\
Cellulose $(\%)^{\mathrm{b}}$ & 44.32 & $\mathrm{ND}$ \\
Hemicellulose $(\%)^{\mathrm{b}}$ & 33.54 & $\mathrm{ND}$ \\
${\text { Lignin }(\%)^{\mathrm{b}}}$ & 8.28 & $\mathrm{ND}$ \\
\hline
\end{tabular}

ND: not determined; CS: corn stover.

${ }^{\mathrm{a}}$ Weight of sample; ${ }^{\mathrm{b}}$ TS of sample.

$\mathrm{KOH}$ treated CS was observed. The cumulative methane yields of $0.5 \%, 1.0 \%, 1.5 \%$, and $2.0 \%$ thermal $\mathrm{KOH}$ treated CS were $167.8 \pm 14.43,205.5 \pm 13.69,243.2 \pm 11.56$, and $255.4 \pm$ $6.60 \mathrm{~mL} / \mathrm{g}_{\mathrm{vs}}$, respectively, and increase in yield was observed with the increasing of $\mathrm{KOH}$ concentration. However, no significant enhancement in yield from thermal $1.5 \% \mathrm{KOH}$ to $2.0 \% \mathrm{KOH}$ treated $\mathrm{CS}$ was observed, while $1.5 \% \mathrm{KOH}-60^{\circ} \mathrm{C}$ treated CS significantly improved the methane yield, $56.40 \%$, $48.43 \%$, and $24.17 \%$, respectively, compared with untreated $\left(155.4 \pm 1.02 \mathrm{~mL} / \mathrm{g}_{\mathrm{vs}}\right)$ and thermal $0.5 \%$ to $1.0 \% \mathrm{KOH}$ treated CS. Li et al. conducted $\mathrm{AD}$ experiment of $1.5 \% \mathrm{KOH}$ treated $\mathrm{CS}$ at $20^{\circ} \mathrm{C}$ and reported only $45.1 \%$ increase in cumulative methane yield with respect to untreated CS [22]. Therefore, mild thermal pretreatment is highly effective for destruction of complex nature of recalcitrance of CS to enhance the digestibility for $\mathrm{AD}$.
3.3. Effect of Copretreatment of Thermal Potassium Hydroxide and Steam Explosion on Anaerobic Digestion of Corn Stover. Copretreatment of CS with thermal KOH and SE was conducted to enhance the anaerobic digestibility. The SE treated CS at $1.2 \mathrm{MPa}$ for $10 \mathrm{~min}$ was tagged as SE, and copretreatments of $0.5 \% \mathrm{KOH}-60^{\circ} \mathrm{C}$ or $1.5 \% \mathrm{KOH}-60^{\circ} \mathrm{C}$ and SE were labeled as $\mathrm{CPTPS}_{0.5 \%}$ and $\mathrm{CPTPS}_{1.5 \%}$, respectively. Figure 2 presents daily and cumulative methane yield of untreated CS and pretreatment effects on CS. Highest peaks of daily methane yield of SE and CPTPS ${ }_{1.5 \%}$ were appeared on the 3rd day and thermal $1.5 \% \mathrm{KOH}-60^{\circ} \mathrm{C}$ and untreated CS were looked on the 4th day of the digestion, meanwhile maximum daily methane yield of CPTPS $1.5 \%$ and SE was $55.2 \pm 2.80$ and $31.9 \pm 1.79 \mathrm{~mL} / \mathrm{g}_{\mathrm{vs}}$, respectively. Thus, $\mathrm{CPTPS}_{1.5 \%}$ significantly deconstructed the lignocellulosic structure of CS and start the digestion faster. Cumulative methane yields of SE, thermal $1.5 \% \mathrm{KOH}-60^{\circ} \mathrm{C}, \mathrm{CPTPS}_{0.5 \%}$, and CPTPS $_{1.5 \%}$ were $217.5 \pm 19.1,243.2 \pm 11.6,236.6 \pm 2.7$, and $292.9 \pm 3.8 \mathrm{~mL} / \mathrm{g}_{\mathrm{vs}}$, respectively. SE, thermal $1.5 \% \mathrm{KOH}-60^{\circ} \mathrm{C}$, CPTPS $_{0.5 \%}$, and CPTPS $1.5 \%$ treated CS significantly improved cumulative methane yields, $39.95 \%, 56.40 \%, 52.24 \%$, and $88.46 \%$, respectively, compared to untreated $\left(155.5 \mathrm{~mL} / \mathrm{g}_{\mathrm{vs}}\right)$. But no significant variance among cumulative methane yields of thermal $1.5 \% \mathrm{KOH}-60^{\circ} \mathrm{C}$, SE, and $\mathrm{CPTPS}_{0.5 \%}$ was observed. Moreover, CPTPS ${ }_{1.5 \%}$ significantly enhanced $23.8 \%$ of cumulative methane yield compared with $\mathrm{CPTPS}_{0.5 \%}$. Therefore, CPTPS ${ }_{1.5 \%}$ was an effective pretreatment method to destroy the lignocellulosic complex structure among all and to improve the biodegradability for methane production.

3.4. Digestion Performance of Untreated and Pretreated CS. Total alkalinity (TA), total ammonia nitrogen, and biodegradability after the $\mathrm{AD}$ of untreated $\mathrm{CS}, 1.5 \% \mathrm{KOH}$ at $60^{\circ} \mathrm{C}$, SE, CPTPS ${ }_{0.5 \%}$, and $\mathrm{CPTPS}_{1.5 \%}$ treated CS were measured to evaluate the digestion process stability performance and presented in Table 2. Alkalinity (carbonate/bicarbonate) 

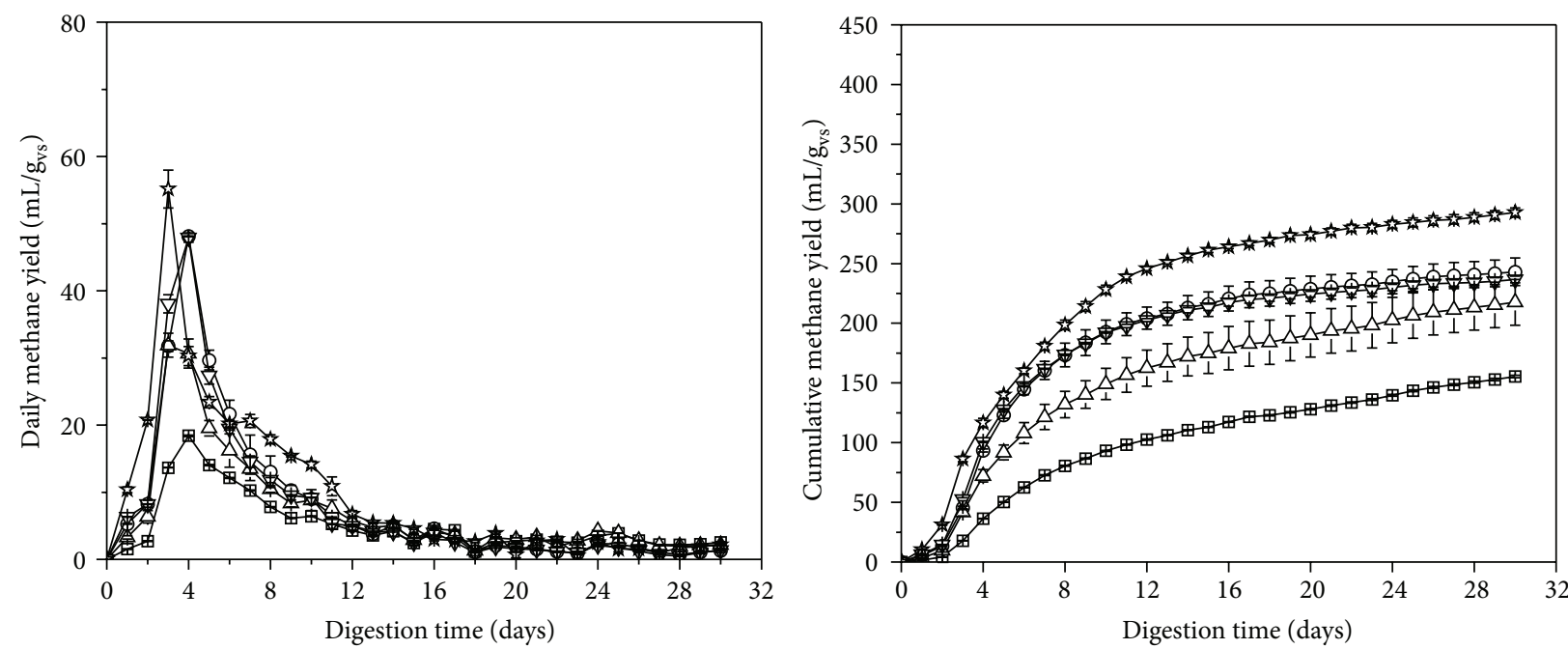

$$
\begin{aligned}
& \rightarrow-\text { Untreated CS } \quad-\nabla-\text { CPTPS }_{0.5 \%} \text { treated CS }
\end{aligned}
$$

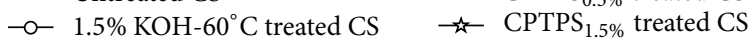

$$
\begin{aligned}
& \triangle-\text { SE treated CS }
\end{aligned}
$$

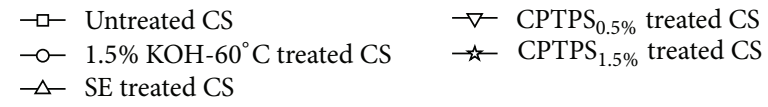

FIGURE 2: Methane yields of untreated, thermal KOH treated, SE treated, and CPTPS treated CS. Error bars were obtained based on $n=3$.

level in the anaerobic digester indicates the capability to counteract the acids concentration to maintain $\mathrm{pH}$ and to avoid the inhibition in the digestion process. TA should fall into the range of 1500 to $3000 \mathrm{mg} \mathrm{CaCO}_{3} / \mathrm{L}$ for optimal operation during $\mathrm{AD}$ process [18]. TA concentrations of the SE and $\mathrm{CPTPS}_{1.5 \%}$ treated CS were $1740 \pm 20$ and $1560 \pm$ 10 and thus were found in the permissible range. Nitrogen is an essential nutrient for anaerobic bacterial culture for digestion process, and tolerable concentration of total ammonia nitrogen (TAN) ranges from $55 \pm 11$ to $150 \mathrm{mg} / \mathrm{L}$ for optimal digestion [28]. Concentration more than this permissible limit causes inhibition/toxicity for AD system. TAN concentration of CPTPS $_{1.5 \%}$ treated CS was $133 \pm 6.0 \mathrm{mg} / \mathrm{L}$ and located in allowable range for AD. Biodegradability $\left(B_{d}\right)$ is ultimate indicator for stable and optimal AD. $B_{d}$ of $1.5 \%$ $\mathrm{KOH}$ at $60^{\circ} \mathrm{C}, \mathrm{SE}, \mathrm{CPTPS}_{0.5 \%}$, and $\mathrm{CPTPS}_{1.5 \%}$ treated CS were $57.21 \%, 51.16 \%, 55.66 \%$, and $68.90 \%$, respectively. $B_{d}$ of CPTPS $1.5 \%$ treated CS was significantly improved $88.46 \%$, $20.51 \%, 34.67 \%$, and $23.81 \%$, respectively, compared with untreated, thermal $1.5 \% \mathrm{KOH}-60^{\circ} \mathrm{C}$ treated, SE treated, and $\mathrm{CPTPS}_{0.5 \%}$ treated CS, while EMY and $B_{d}$ of combined treated CS with $\mathrm{KOH}$ and SE were only $258.8 \mathrm{~mL} / \mathrm{g}_{\mathrm{vs}}$ and $62.5 \%$, respectively, which indicated significant differences compared with CPTPS ${ }_{1.5 \%}$ [22]. Therefore, considering the concentration of TA, TAN, and biodegradability after AD, CPTPS $_{1.5 \%}$ treated CS digestion process was stable and the performance of methane production was very well.

3.5. Kinetics Analysis of Methane Production. The simulation of cumulative biogas production of untreated, thermal $\mathrm{KOH}$ treated, SE treated, and CPTPS treated CS were analyzed by applying three kinetic models: first-order, modified Gompertz, and Cone models, and three plots are shown in Figure 3. $R^{2}$ values of first-order, modified Gompertz, and Cone models were ranged from 0.971 to $0.987,0.977$ to 0.991 , and 0.993 to 0.998 , respectively. $R^{2}$ of Cone model showed the best fit and well simulated the cumulative methane production of untreated, thermal $\mathrm{KOH}$ treated, SE treated, and CPTPS treated CS. These three models describe the different kinetics functions of AD process. So the following parameters of three kinetic models $\left(k, \mu_{m}, \lambda\right.$, and $\left.B_{0}\right)$ were estimated and presented in Table 3 for the kinetics of methane production.

According to prediction of first-order and Cone models, hydrolysis rate $(k)$ value increased from untreated to pretreated CS; meanwhile, modified Gompertz model predicted that the lag phase time $(\lambda)$ was dropped $(0.45 \pm 0.49$ to $0.41 \pm 0.23$ day) from untreated to CPTPS $_{1.5 \%}$ treated CS. Drop of $\lambda$ implied a synergistic effect of CPTPS treatment on complex lignocellulosic structure deconstruction. Consequently, maximum methane production rate $\left(\mu_{m}\right)$ value was increased from untreated to treated CS, and $\mathrm{CPTPS}_{1.5 \%}$ treated CS was looked high as $28.28 \pm 1.24$. Besides all these digestion parameters, methane production potential was estimated to be lower $\left(281.6 \pm 2.4 \mathrm{~mL} \mathrm{CH}_{4} / \mathrm{g}_{\mathrm{vs}}\right)$ by modified Gompertz and slightly higher $\left(303.5 \pm 2.3 \mathrm{~mL} \mathrm{CH}_{4} / \mathrm{g}_{\mathrm{vs}}\right)$ by Cone model of CPTPS $_{1.5 \%}$ treated CS with respect to EMY value of $292.9 \pm 3.8 \mathrm{~mL} \mathrm{CH} 4 / g_{v s}$, while first-order model imitated $299.1 \pm 4.1 \mathrm{~mL} \mathrm{CH} / \mathrm{g}_{\mathrm{vs}}$ and it was approximately near to EMY of CPTPS ${ }_{1.5 \%}$ treated CS. The results of kinetic parameters showed that CPTPS $_{1.5 \%}$ pretreatment effectively deconstructed the complex nature of lignocellulosic structure and enhanced the methane yield as compared to other treatments. In spite of all these, EMY indicated that there was still a lot of space to do more research in future to improve the output yield of CS.

3.6. Changes of Physicochemical Structures. Physicochemical structural changes of untreated, $\mathrm{KOH}$ treated, SE treated, and CPTPS treated CS were examined by SEM, FTIR, and XRD. 


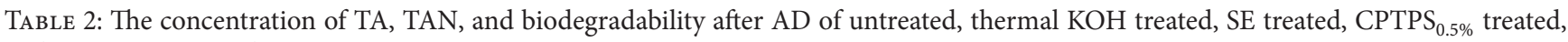
and CPTPS $_{1.5 \%}$ treated CS.

\begin{tabular}{lccc}
\hline Samples & $\mathrm{TA}\left(\mathrm{mg} \mathrm{CaCO}_{3} / \mathrm{L}\right)$ & $\mathrm{TAN}(\mathrm{mg} / \mathrm{L})$ & $B_{d}(\%)$ \\
\hline Untreated CS & $1085 \pm 55$ & $181.50 \pm 8.50$ & 36.57 \\
$1.5 \% \mathrm{KOH}-60^{\circ} \mathrm{C}$ treated CS & $1400 \pm 20$ & $173.50 \pm 1.50$ & 57.21 \\
SE treated CS & $1740 \pm 20$ & $195.00 \pm 11.00$ & 51.16 \\
CPTPS $_{0.5 \%}$ treated CS & $1420 \pm 60$ & $192.50 \pm 5.50$ & 55.66 \\
CPTPS $_{1.5 \%}$ treated CS & $1560 \pm 10$ & $133.00 \pm 6.00$ & 68.90 \\
\hline
\end{tabular}

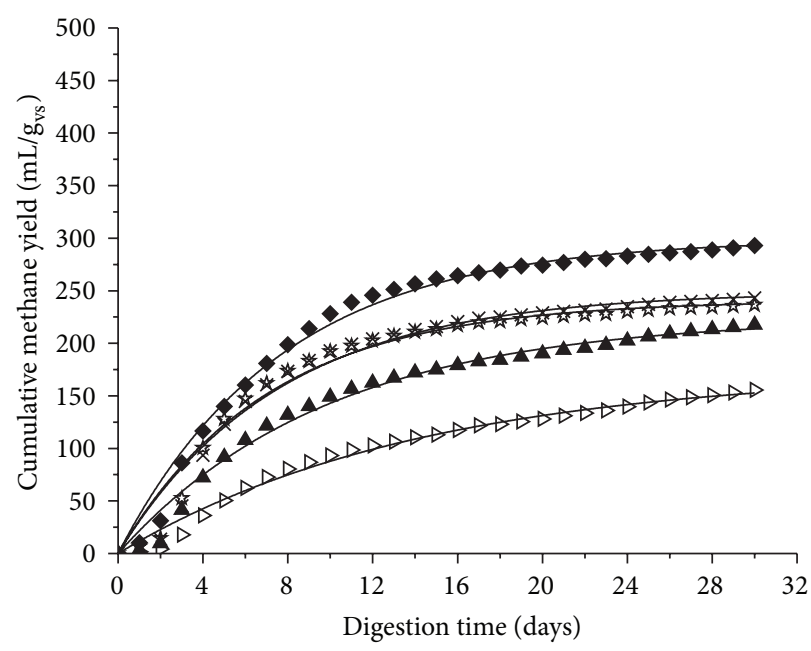

$\triangleright$ Untreated CS

$\times \quad 1.5 \% \mathrm{KOH}-60^{\circ} \mathrm{C}$ treated CS

- SE treated CS
* $\mathrm{CPTPS}_{0.5 \%}$ treated CS

- CPTPS $_{1.5 \%}$ treated CS

— First-order model

(a)

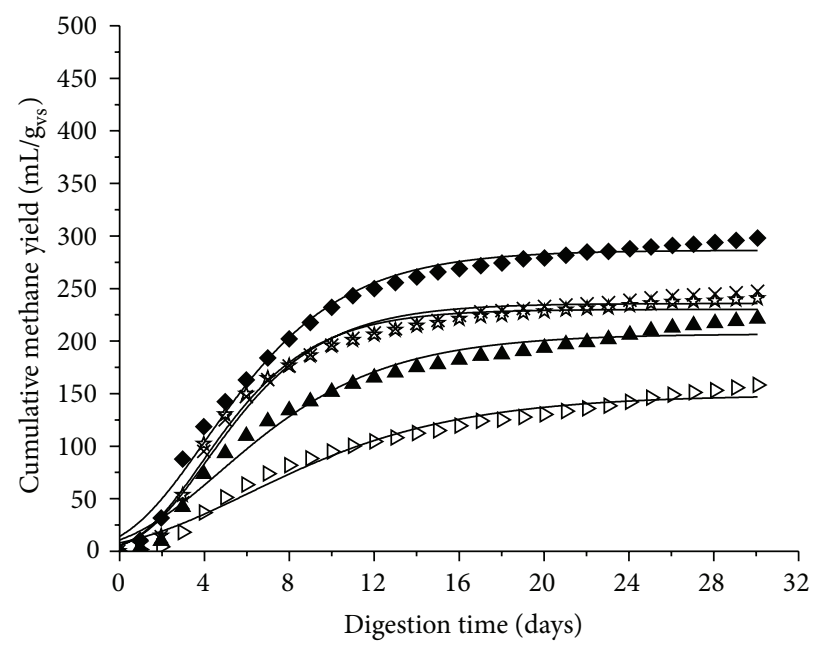

$\triangleright$ Untreated CS

$\times \quad 1.5 \% \mathrm{KOH}-60^{\circ} \mathrm{C}$ treated CS

- SE treated CS

* $\mathrm{CPTPS}_{0.5 \%}$ treated CS

- CPTPS $_{1.5 \%}$ treated CS

_ Modified Gompertz model

(b)

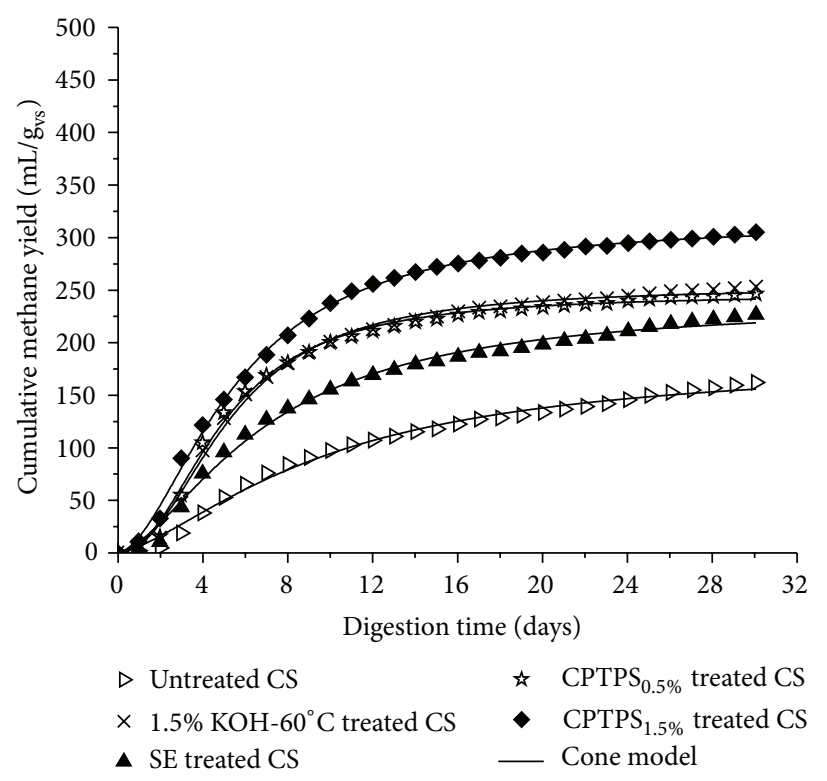

(c)

FIGURE 3: First-order, modified Gompertz, and Cone plots of cumulative methane yields of untreated, thermal KOH treated, SE treated, and CPTPS treated CS. 


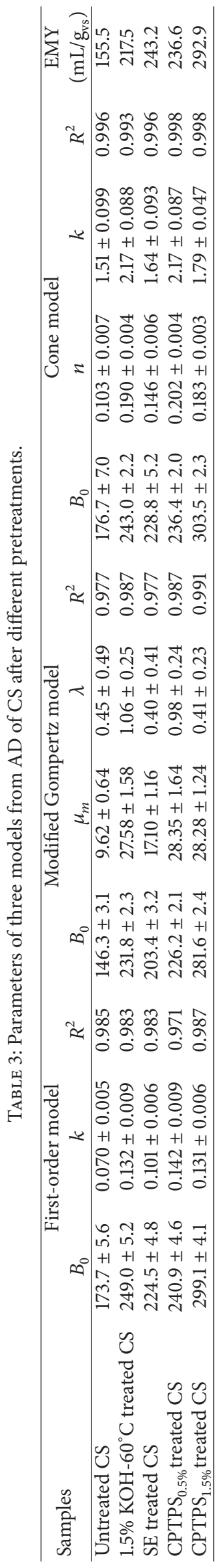




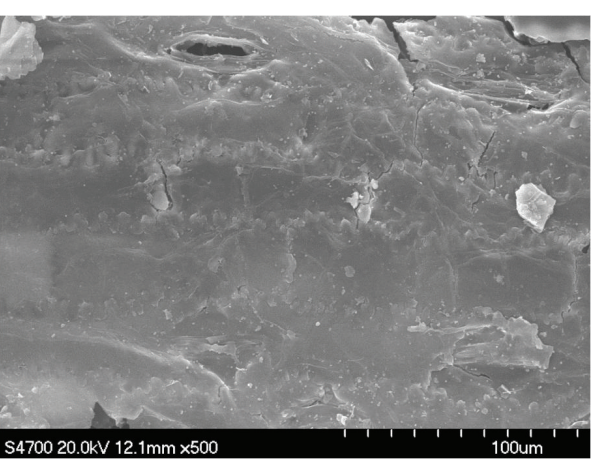

(a)

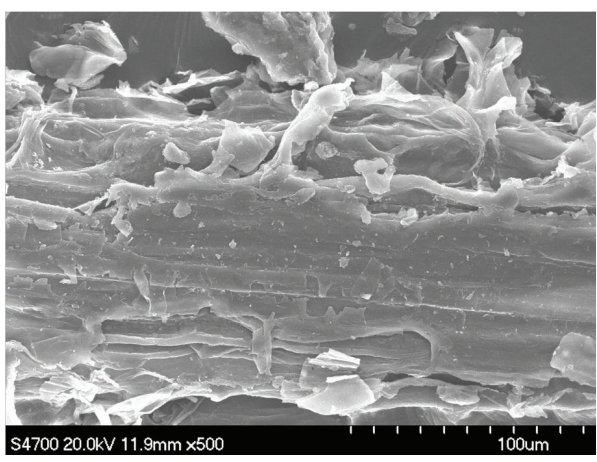

(c)

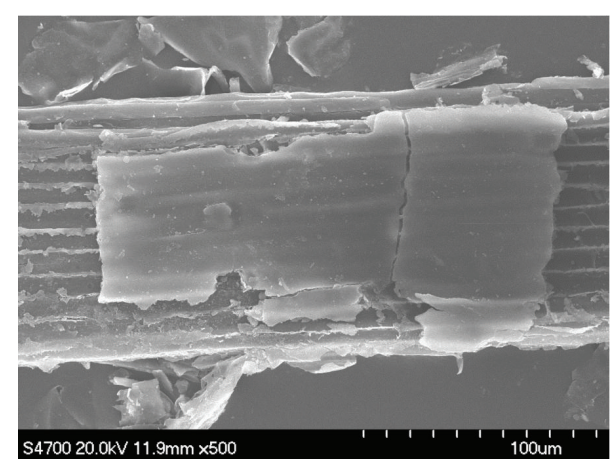

(b)

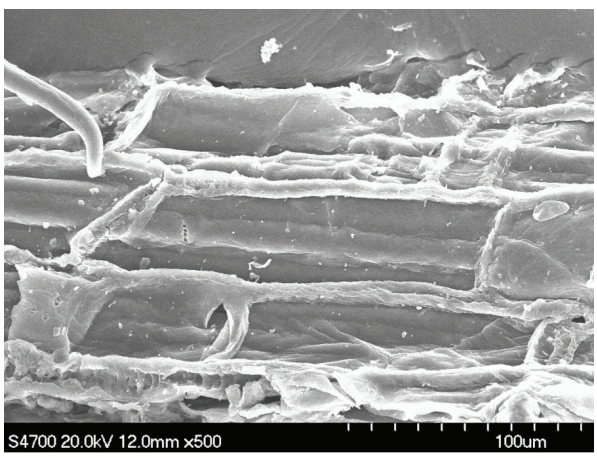

(d)

FIGURE 4: SEM images (500x) of untreated (a), SE treated (b), thermal KOH treated (c), and CPTPS . $_{1.5 \%}$ treated (d) CS.

3.6.1. SEM Analysis. The SEM images of untreated and treated CS are presented in Figure 4 for the surface morphological comparison. The morphology of untreated CS image "a" revealed more rigid and smooth surface than image " $b$ " of SE treated CS, while image "b" was more dense and compact than image " $c$ " of thermal KOH treated CS. On the other hand, image "d" of CPTPS ${ }_{1.5 \%}$ treated CS was extremely smashed, uneven, and ruptured as compared to images "a," "b," and "c." It indicated that CPTPS treatment exposed and increased the surface area. Most of lignin and hemicellulose of CS were probably dissolved or broken down, and the cell wall structure was deconstructed.

3.6.2. FTIR Analysis. Changes in functional group structure of SE treated, thermal $\mathrm{KOH}$ treated, and $\mathrm{CPTPS}_{1.5 \%}$ treated CS with respect to untreated CS were examined by FTIR spectroscopy and the spectra are presented in Figure 5. All the samples of CS showed the similar trend, while the following bands showed some changes: $1734 \mathrm{~cm}^{-1}, 1605 \mathrm{~cm}^{-1}$, and $1163 \mathrm{~cm}^{-1}$. The wavenumber around $1734 \mathrm{~cm}^{-1}$ band stands for carbonyl of hemicellulose, and reduction from untreated CS to CPTPS ${ }_{1.5 \%}$ treated CS was observed; in other words, copretreatment of thermal $\mathrm{KOH}$ and SE caused breakdown of ester bond in hemicelluloses and lignin. Beside this, the peak at $1605 \mathrm{~cm}^{-1}$ of thermal $\mathrm{KOH}-60^{\circ} \mathrm{C}$ treated $\mathrm{CS}$ was weaker than SE treated CS. It indicated more degradation of lignin in thermal $\mathrm{KOH}$ treatment than SE due to deconstruction of aromatic rings. Furthermore, peak at $1163 \mathrm{~cm}^{-1}$ increased

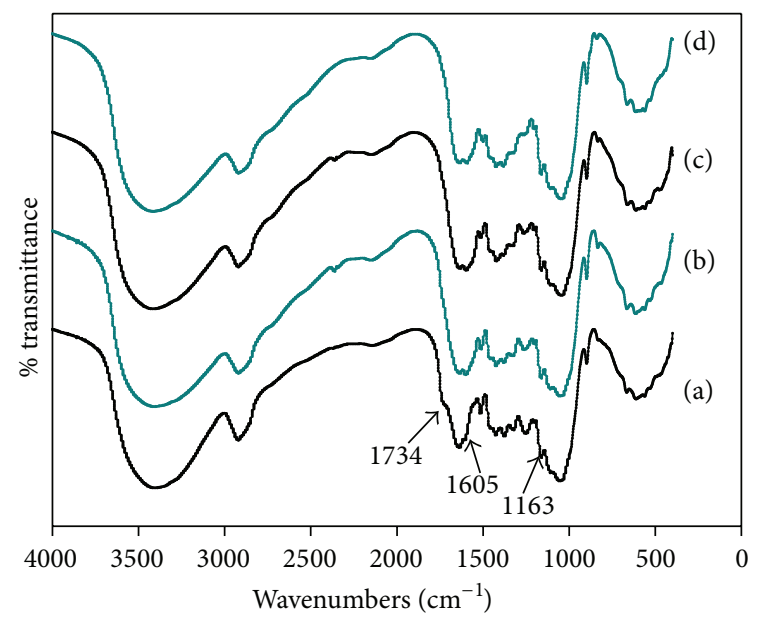

FIGURE 5: FTIR spectra of untreated (a), SE treated (b), thermal $\mathrm{KOH}$ treated (c), and $\mathrm{CPTPS}_{1.5 \%}$ treated (d) CS.

in CPTPS $_{1.5 \%}$ treated CS, compared to untreated, SE treated, and thermal $\mathrm{KOH}$ treated $\mathrm{CS}$, because of changes in cellulose from crystalline to amorphous, lignin degradation or removal, and hemicellulose destruction. These indicators proved that CPTPS treatment was more effective to deconstruct the lignocellulosic structure for improving the anaerobic digestibility of CS. 


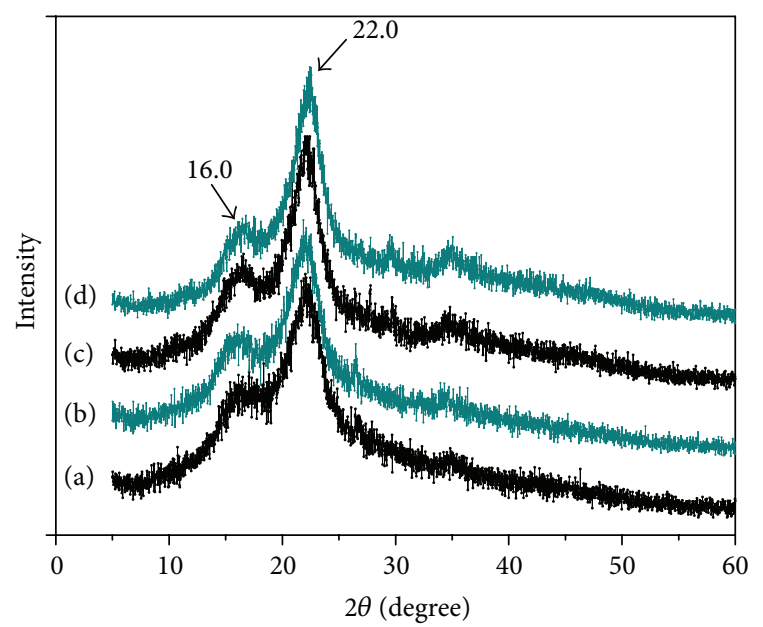

FIGURE 6: XRD patterns of untreated (a), SE treated (b), thermal $\mathrm{KOH}$ treated (c), and $\mathrm{CPTPS}_{1.5 \%}$ treated (d) CS.

3.6.3. XRD Analysis. XRD was applied to analyze the cellulose crystalline structures of untreated, thermal $\mathrm{KOH}$ treated, SE treated, and CPTPS $_{1.5 \%}$ treated CS, and the spectra are presented in Figure 6. Similar pattern in XRD was observed, while changes appeared in $2 \theta$ of $22^{\circ}$ and $18^{\circ}$ due to crystalline variation. The collective effect of thermal $\mathrm{KOH}$ and SE is probably swelling the cellulose during the pretreatment process of CS, while cellulose crystal lattice may not change. The calculated CrI values of untreated, $\mathrm{SE}$ treated, thermal $\mathrm{KOH}$ treated, and $\mathrm{CPTPS}_{1.5 \%}$ treated CS were $48.14 \%, 57.49 \%, 58.07 \%$, and $65.52 \%$, respectively. Maximum CrI value was appeared in $\mathrm{CPTPS}_{1.5 \%}$ treated CS, compared to SE and thermal $\mathrm{KOH}$ treatments. It implied that CPTPS had synergistic effect to remove noncrystalline hemicellulose and lignin as compared to SE and thermal $\mathrm{KOH}$. Therefore, CPTPS achieved the higher CrI values and improved the biodegradability of CS.

\section{Conclusion}

Three different types of pretreatment (KOH, SE, and CPTPS) were employed to CS for evaluation of their impacts on deconstruction of lignocellulosic structure, to improve the digestibility and enhance the methane yield. CPTPS ${ }_{1.5 \%}$ effectively altered the recalcitant nature and complex structure of lignocellulosic CS and increased the cumulative methane yield $\left(292.9 \mathrm{~mL} / \mathrm{g}_{\mathrm{vs}}\right)$ of CS by $20.50 \%, 34.66 \%$, and $88.46 \%$, compared with thermal $\mathrm{KOH}-60^{\circ} \mathrm{C}$ treated, SE treated, and untreated CS. CPTPS might be a potential pretreatment method to destroy the lignocellulosic structure and to improve the digestibility of CS for future AD industry.

\section{Competing Interests}

The authors declare that there is no conflict of interests regarding the publication of this paper.

\section{Acknowledgments}

The authors would like to thank the National Hi-tech R\&D Program of China (863 Program, 2012AA101803), the National Key Technology Support Program of China (2012BAC25B06), and the Fundamental Research Funds for the Central Universities (YS1407) for financial supports.

\section{References}

[1] National Bureau of Statistics of China, China Statistical Yearbook, National Bureau of Statistics of China, Beijing, China, 2013.

[2] T. Shi, Y. Liu, L. Zhang, L. Hao, and Z. Gao, "Burning in agricultural landscapes: an emerging natural and human issue in China," Landscape Ecology, vol. 29, no. 10, pp. 1785-1798, 2014.

[3] A. Oniszk-Popławska, M. Matyka, and E. D. Ryńska, "Evaluation of a long-term potential for the development of agricultural biogas plants: a case study for the Lubelskie Province, Poland," Renewable and Sustainable Energy Reviews, vol. 36, pp. 329-349, 2014.

[4] A. Teghammar, K. Karimi, I. Sárvári Horváth, and M. J. Taherzadeh, "Enhanced biogas production from rice straw, triticale straw and softwood spruce by NMMO pretreatment," Biomass and Bioenergy, vol. 36, pp. 116-120, 2012.

[5] F. Theuretzbacher, J. Lizasoain, C. Lefever et al., "Steam explosion pretreatment of wheat straw to improve methane yields: investigation of the degradation kinetics of structural compounds during anaerobic digestion," Bioresource Technology, vol. 179, pp. 299-305, 2015.

[6] Z.-H. Liu, L. Qin, M.-J. Jin et al., "Evaluation of storage methods for the conversion of corn stover biomass to sugars based on steam explosion pretreatment," Bioresource Technology, vol. 132, pp. 5-15, 2013.

[7] I. Ballesteros, M. Ballesteros, C. Cara et al., "Effect of water extraction on sugars recovery from steam exploded olive tree pruning," Bioresource Technology, vol. 102, no. 11, pp. 6611-6616, 2011.

[8] A. Elliston, D. R. Wilson, N. Wellner, S. R. A. Collins, I. N. Roberts, and K. W. Waldron, "Effect of steam explosion on waste copier paper alone and in a mixed lignocellulosic substrate on saccharification and fermentation," Bioresource Technology, vol. 187, pp. 136-143, 2015.

[9] J. Wang, Z.-B. Yue, T.-H. Chen, S.-C. Peng, H.-Q. Yu, and H.-Z. Chen, "Anaerobic digestibility and fiber composition of bulrush in response to steam explosion," Bioresource Technology, vol. 101, no. 17, pp. 6610-6614, 2010.

[10] M. Koyama, S. Yamamoto, K. Ishikawa, S. Ban, and T. Toda, "Enhancing anaerobic digestibility of lignin-rich submerged macrophyte using thermochemical pre-treatment," Biochemical Engineering Journal, vol. 99, pp. 124-130, 2015.

[11] H. Jung, G. Baek, J. Kim, S. G. Shin, and C. Lee, "Mildtemperature thermochemical pretreatment of green macroalgal biomass: effects on solubilization, methanation, and microbial community structure," Bioresource Technology, vol. 199, pp. 326335,2016

[12] Y. Zheng, J. Zhao, F. Xu, and Y. Li, "Pretreatment of lignocellulosic biomass for enhanced biogas production," Progress in Energy and Combustion Science, vol. 42, no. 1, pp. 35-53, 2014. 
[13] G. Feijoo, M. Soto, R. Méndez, and J. M. Lema, "Sodium inhibition in the anaerobic digestion process: antagonism and adaptation phenomena," Enzyme and Microbial Technology, vol. 17, no. 2, pp. 180-188, 1995.

[14] M. Zheng, X. Li, L. Li, X. Yang, and Y. He, "Enhancing anaerobic biogasification of corn stover through wet state $\mathrm{NaOH}$ pretreatment," Bioresource Technology, vol. 100, no. 21, pp. 51405145, 2009.

[15] I. Angelidaki, M. Alves, D. Bolzonella et al., "Defining the biomethane potential (BMP) of solid organic wastes and energy crops: a proposed protocol for batch assays," Water Science \& Technology, vol. 59, no. 5, pp. 927-934, 2009.

[16] W. F. Owen, D. C. Stuckey, J. B. Healy Jr., L. Y. Young, and P. L. McCarty, "Bioassay for monitoring biochemical methane potential and anaerobic toxicity," Water Research, vol. 13, no. 6, pp. 485-492, 1979.

[17] APHA, American Public Health Association Yearbook, American Public Health Association, Washington, DC, USA, 18th edition, 1998.

[18] L. Li, L. Feng, R. Zhang et al., "Anaerobic digestion performance of vinegar residue in continuously stirred tank reactor," Bioresource Technology, vol. 186, pp. 338-342, 2015.

[19] B. Rincón, S. Heaven, C. J. Banks, and Y. Zhang, "Anaerobic digestion of whole-crop winter wheat silage for renewable energy production," Energy \& Fuels, vol. 26, no. 4, pp. 23572364, 2012.

[20] Y. Li, L. Feng, R. Zhang et al., "Influence of inoculum source and pre-incubation on bio-methane potential of chicken manure and corn stover," Applied Biochemistry and Biotechnology, vol. 171, no. 1, pp. 117-127, 2013.

[21] P. J. Van Soest, J. B. Robertson, and B. A. Lewis, "Methods for dietary fiber, neutral detergent fiber, and nonstarch polysaccharides in relation to animal nutrition," Journal of Dairy Science, vol. 74, no. 10, pp. 3583-3597, 1991.

[22] J. Li, R. Zhang, M. A. H. Siddhu et al., "Enhancing methane production of corn stover through a novel way: sequent pretreatment of potassium hydroxide and steam explosion," Bioresource Technology, vol. 181, pp. 345-350, 2015.

[23] H. M. El-Mashad and R. Zhang, "Biogas production from co-digestion of dairy manure and food waste," Bioresource Technology, vol. 101, no. 11, pp. 4021-4028, 2010.

[24] Y. Sun, L. Lin, C. Pang et al., "Hydrolysis of cotton fiber cellulose in formic acid," Energy \& Fuels, vol. 21, no. 4, pp. 2386-2389, 2007.

[25] A. M. Buswell and H. F. Mueller, "Mechanism of methane fermentation," Industrial \& Engineering Chemistry, vol. 44, no. 3, pp. 550-552, 1952.

[26] E. Elbeshbishy, G. Nakhla, and H. Hafez, "Biochemical methane potential (BMP) of food waste and primary sludge: influence of inoculum pre-incubation and inoculum source," Bioresource Technology, vol. 110, pp. 18-25, 2012.

[27] H. M. El-Mashad, "Kinetics of methane production from the codigestion of switchgrass and Spirulina platensis algae," Bioresource Technology, vol. 132, pp. 305-312, 2013.

[28] D. P. B. T. B. Strik, A. M. Domnanovich, and P. Holubar, "A pHbased control of ammonia in biogas during anaerobic digestion of artificial pig manure and maize silage," Process Biochemistry, vol. 41, no. 6, pp. 1235-1238, 2006. 

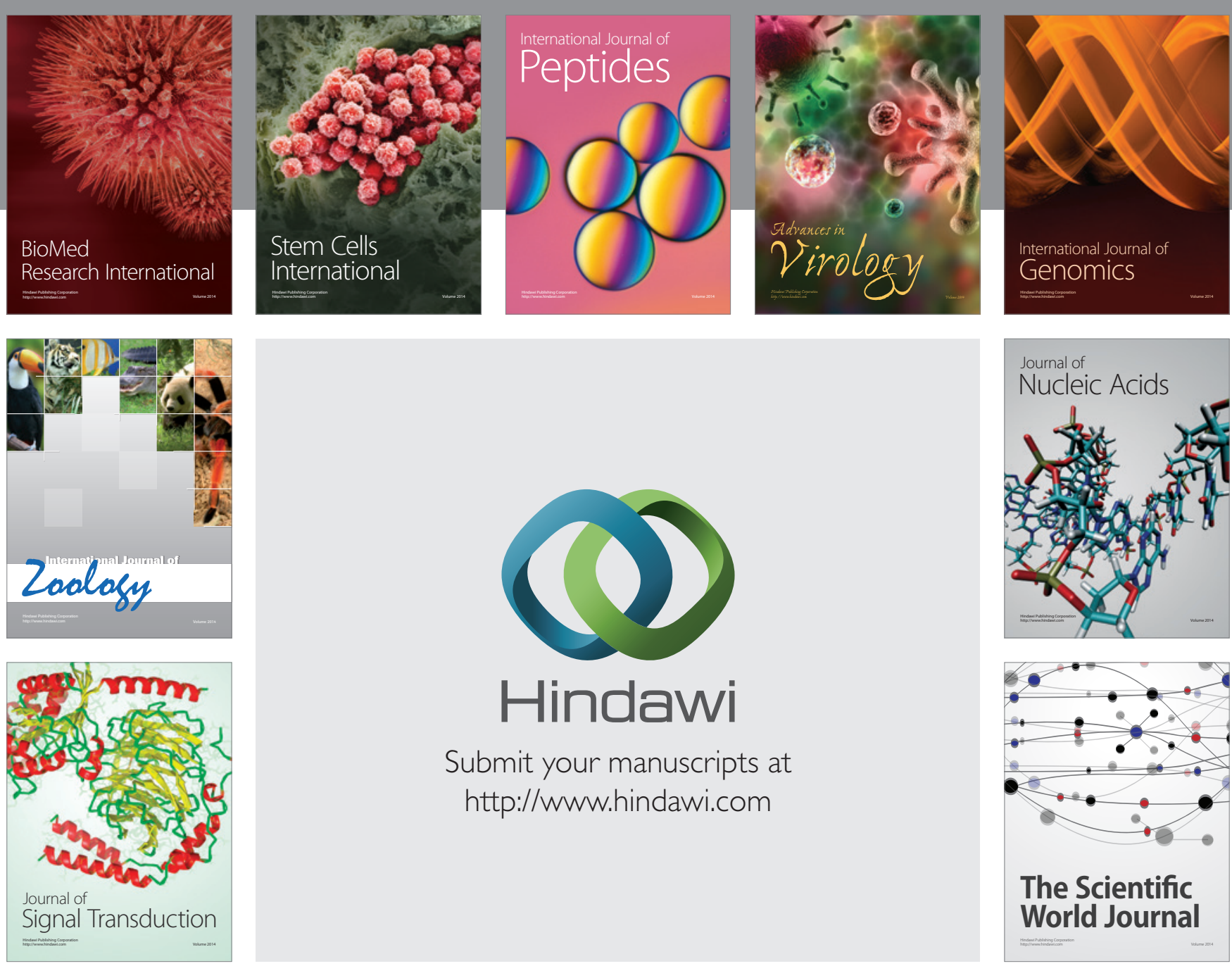

Submit your manuscripts at

http://www.hindawi.com
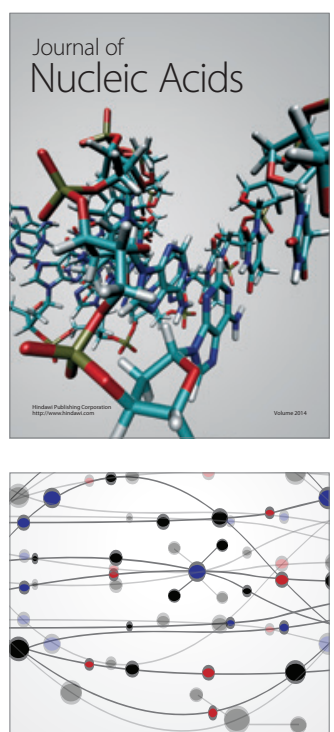

The Scientific World Journal
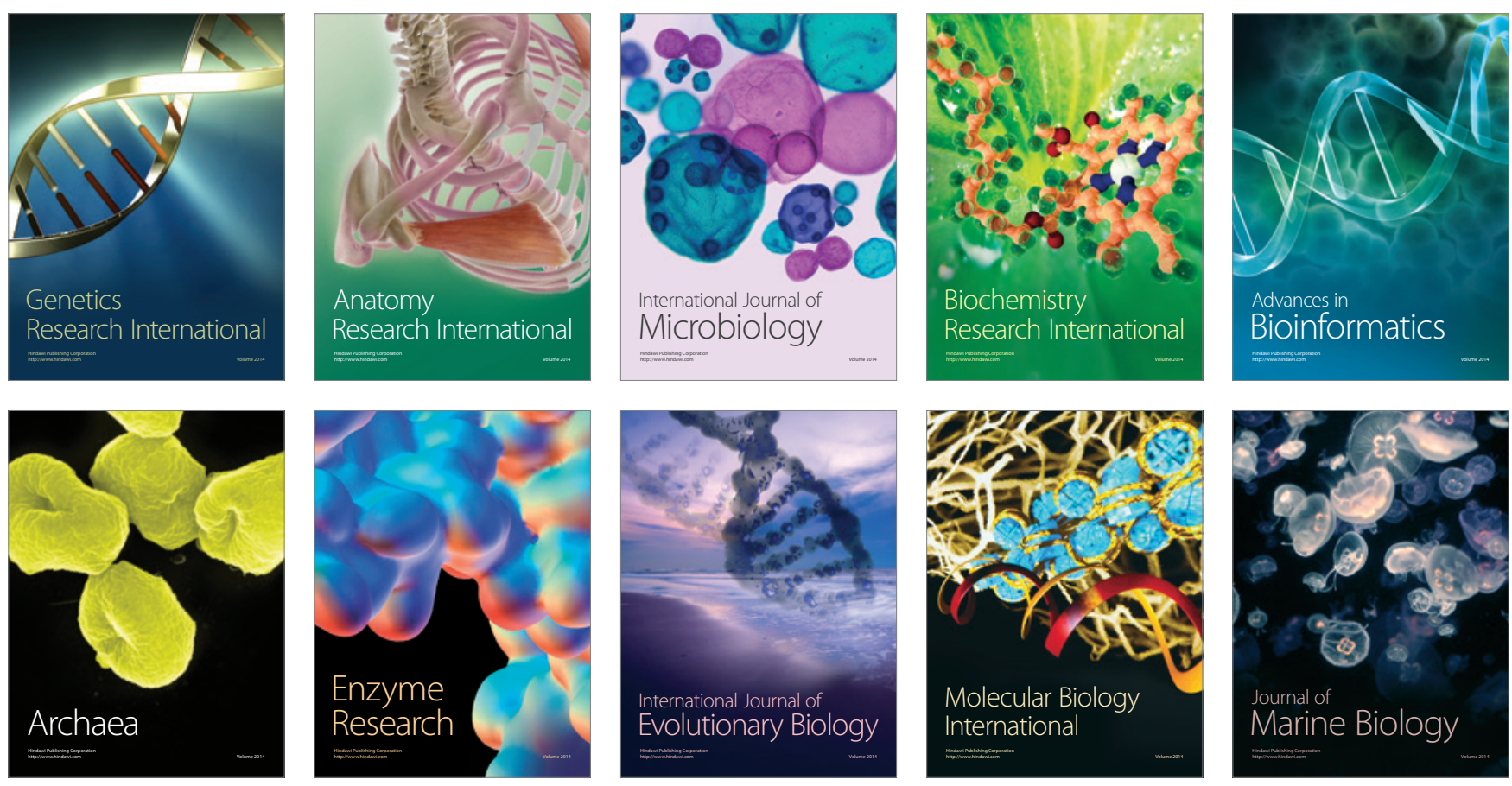